\title{
Computation Analysis of Buckling Loads of Thin-Walled Members with Open Sections
}

\author{
Lihua Huang, ${ }^{1}$ Bin $\mathrm{Li}^{1}{ }^{1}$ and Yuefang Wang ${ }^{2}$ \\ ${ }^{1}$ Faculty of Infrastructure Engineering, Dalian University of Technology, Dalian 116024, China \\ ${ }^{2}$ Department of Engineering Mechanics, Dalian University of Technology, Dalian 116024, China \\ Correspondence should be addressed to Lihua Huang; lhhang@dlut.edu.cn
}

Received 28 July 2016; Revised 5 October 2016; Accepted 24 October 2016

Academic Editor: Fazal M. Mahomed

Copyright (c) 2016 Lihua Huang et al. This is an open access article distributed under the Creative Commons Attribution License, which permits unrestricted use, distribution, and reproduction in any medium, provided the original work is properly cited.

\begin{abstract}
The computational methods for solving buckling loads of thin-walled members with open sections are not unique when different concerns are emphasized. In this paper, the buckling loads of thin-walled members in linear-elastic, geometrically nonlinear-elastic, and nonlinear-inelastic behaviors are investigated from the views of mathematical formulation, experiment, and numerical solution. The differential equations and their solutions of linear-elastic and geometrically nonlinear-elastic buckling of thin-walled members with various constraints are derived. Taking structural angle as an example, numerical analysis of elastic and inelastic buckling is carried out via ANSYS. Elastic analyses for linearized buckling and nonlinear buckling are realized using finite elements of beam and shell and are compared with the theoretical results. The effect of modeling of constraints on numerical results is studied when shell element is applied. The factors that influence the inelastic buckling load in numerical solution, such as modeling of constraint, loading pattern, adding rib, scale factor of initial defect, and yield strength of material, are studied. The noteworthy problems and their solutions in numerically buckling analysis of thin-walled member with open section are pointed out.
\end{abstract}

\section{Introduction}

Thin-walled members with open section are widely used in structures for their high ratio of strength to weight. The loading capacity of these structures is closely related to the overall and local stability of thin-walled members, leading to the investigation of the elastic and inelastic buckling analysis of these members. In engineering practice, the failure modes of compressive thin-walled members are generally analyzed according to the type of stresses developed within the member at the time of failure. For most long-slender members, the failure of buckling is dominantly referred to as elastic instability since the compressive stress remains elastic. For intermediate compressive members, inelastic buckling generally occurs as a result of the compressive stresses inside the members being greater than the materials' yield strength. By contrast, short-length compressive members, also known as stocky members, do not become unstable; rather the material simply yields or fractures.

The computational methods of buckling for elastic and inelastic instability of thin-walled compressive member are discussed in this paper. Problems for linearized, geometrically and physically nonlinear buckling are investigated based on mathematical formulation and numerical solutions. In the classical theory of elastic buckling, the coupling terms of translational displacements and axial rotation are ignored in the regime of small deformation [1-3]. Mohri et al. derived governing equations of post flexural-torsional buckling of thin-walled compressive member with open section supported by pins at two ends considering large deformation and coupling terms of displacement [4]. As to the inelastic buckling problem, Finite Element Method is the most effective way to obtain the buckling loads as well as the primary and secondary equilibrium paths of members with material and geometrical nonlinear behavior. Models of beam and shell elements are generally used to solve the higher order nonlinear problems in instability analysis. The buckling load of overall instability can be determined by adopting beam element, and both local and overall instability can be simulated via shell element. By taking structural angles with equal legs as an example in this paper, elastic analyses including linear buckling and nonlinear buckling are 


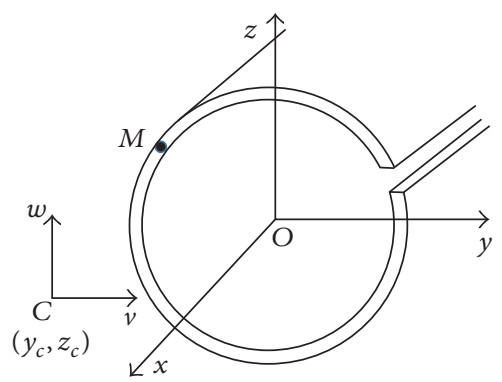

FIgURE 1: Model of a thin-walled member with open section.

realized using the elements of beam and shell. The effects of modeling of constraints on numerical results are studied when shell elements are applied. Analysis of linearized buckling analysis and nonlinearized buckling analysis of material and geometrical nonlinearity are conducted and compared with experimental and theoretical results. The factors that affect the inelastic buckling loads in numerical analysis, such as modeling of constraints, scale factors of initial defects, adding rib and loading modes, are discussed. The noteworthy problems and their solutions in numerical buckling analysis of thin-walled member with open section are pointed out.

\section{Mathematical Formulation}

A thin-walled compressive member with an arbitrary open section is shown in Figure 1, where point $O$ is the centroid of the section and point $C\left(y_{c}, z_{c}\right)$ is the shear center. $O x y z$ is the centroidal principal axis.

2.1. Equations of Classical Linear-Elastic Buckling. The equations of classical stability for a thin-walled member are a set of fourth-order linear differential equations with constant coefficients [1]:

$$
\begin{aligned}
& E I_{z} v^{(4)}+P v^{\prime \prime}+P z_{c} \theta_{x}^{\prime \prime}=0, \\
& E I_{y} w^{(4)}+P w^{\prime \prime}-P y_{c} \theta_{x}^{\prime \prime}=0, \\
& P z_{C} v^{\prime \prime}-P y_{C} w^{\prime \prime}+E I_{\omega} \theta_{x}^{(4)}+\left(P I_{0}-G J\right) \theta_{x}^{2}=0, \\
& I_{0}=\frac{\left(I_{y}+I_{z}\right)}{A}+y_{c}^{2}+z_{c}^{2},
\end{aligned}
$$

where $E$ and $G$ are the elastic constants. $P$ is an axially compressive force applied at the centroid. The displacements of shear center in $y$ and $z$ directions are denoted by $v$ and $w$, respectively. The rotation of the cross section is represented by $\theta_{x} . J$ is free torsional moment of inertia, and $I_{\omega}$ denotes the principal warping moment of inertia. The critical load is determined through solving the eigenvalue problems, yielding

$$
\left|\begin{array}{ccc}
P_{z}-P & 0 & -P z_{c} \\
0 & P_{y}-P & P y_{c} \\
-P z_{c} & P y_{c} & P_{\omega} I_{0}-P I_{0}
\end{array}\right|=0
$$

in which $P_{x}=E I_{x} \lambda^{2}, P_{y}=E I_{y} \lambda^{2}$, and $P_{\omega}=\left(E I_{\omega} \lambda^{2}+G J\right) / I_{0}$. $\lambda=n \pi / L$ for member pinned at two ends where $n=$ $1,2,3, \ldots$, and $L$ denotes the length of the member. $\lambda=$ $2 n \pi / L$ for two fixed ends. For a member fixed at one end and free at the other end, $\lambda=n \pi /(2 L)$. For a member fixed at one end and pinned at the other end, $\lambda=4.493 / L$.

\subsection{Formulation of Geometrically Nonlinear-Elastic-Buckling.}

On the basis of literature [4], the transversal displacements $v_{M}$ and $w_{M}$ of any point $M$ on the cross section when the member is twisted at an angle $\theta_{x}$ are expressed by

$$
\begin{aligned}
v_{M} & =v-\left(z-z_{C}\right) \sin \theta_{x}-\left(y-y_{C}\right)\left(1-\cos \theta_{x}\right), \\
w_{M} & =w+\left(y-y_{C}\right) \sin \theta_{x}-\left(z-z_{C}\right)\left(1-\cos \theta_{x}\right) .
\end{aligned}
$$

The axial displacement $u_{M}$ is expressed by

$$
\begin{aligned}
u_{M}= & u-y\left(v^{\prime} \cos \theta_{x}+w^{\prime} \sin \theta_{x}\right) \\
& -z\left(w^{\prime} \cos \theta_{x}-v^{\prime} \sin \theta_{x}\right)+\omega \theta_{x}^{\prime},
\end{aligned}
$$

where $u, v$, and $w$ are the displacements of shear center in $x$, $y$, and $z$ directions.

The Green strain tensor that incorporates large displacements is defined by

$$
\varepsilon_{i j}=\frac{1}{2}\left(\frac{\partial u_{i}}{\partial x_{j}}+\frac{\partial u_{j}}{\partial x_{i}}+\frac{\partial u_{k}}{\partial x_{i}} \frac{\partial u_{k}}{\partial x_{j}}\right) .
$$

Hence, the strains of point $M$ can be expressed through

$$
\begin{aligned}
\varepsilon_{x x}= & u^{\prime}-y\left(v^{\prime \prime} \cos \theta_{x}+w^{\prime \prime} \sin \theta_{x}\right) \\
& -z\left(w^{\prime \prime} \cos \theta_{x}-v^{\prime \prime} \sin \theta_{x}\right)+\omega \theta_{x}^{\prime \prime} \\
& +\frac{1}{2}\left(v^{\prime 2}+w^{\prime 2}+R^{2} \theta_{x}^{\prime 2}\right) \\
& -y_{C} \theta_{x}^{\prime}\left(w^{\prime} \cos \theta_{x}-v^{\prime} \sin \theta_{x}\right) \\
& +z_{C} \theta_{x}^{\prime}\left(v^{\prime} \cos \theta_{x}+w^{\prime} \sin \theta_{x}\right), \\
\varepsilon_{x y}= & -\frac{1}{2}\left(z-z_{C}-\frac{\partial \omega}{\partial y}\right) \theta_{x}^{\prime}, \\
\varepsilon_{x z}= & \frac{1}{2}\left(y-y_{C}+\frac{\partial \omega}{\partial z}\right) \theta_{x}^{\prime},
\end{aligned}
$$

where

$$
R^{2}=\left(y-y_{C}\right)^{2}+\left(z-z_{C}\right)^{2} .
$$

Based on the principle of virtual work, one obtains

$$
\delta(U-W)=0,
$$

where

$$
\begin{aligned}
& \delta U=\int_{L} \int_{A}\left(\sigma_{x x} \delta \varepsilon_{x x}+2 \sigma_{x y} \delta \varepsilon_{x y}+2 \sigma_{x z} \delta \varepsilon_{x z}\right) \mathrm{d} A \mathrm{~d} x, \\
& \delta W=\int\left(q_{x} \delta u+q_{y} \delta v+q_{z} \delta w+m_{x} \delta \theta_{x}\right) \mathrm{d} x .
\end{aligned}
$$


Consequently, the governing equations considering large deformation and coupling terms are derived as follows:

$$
\begin{aligned}
& N=-P, \\
& E I_{y}\left(w^{(4)}+3 w^{\prime} w^{\prime \prime} w^{\prime \prime \prime}+w^{\prime \prime 3}+\frac{w^{(4)} w^{\prime 2}}{2}\right)-N\left(w^{\prime \prime}\right. \\
& \left.-y_{c} \theta_{x}^{\prime \prime}+z_{c}\left(\theta_{x} \theta_{x}^{\prime \prime}+\theta_{x}^{\prime 2}\right)\right)+\left(E I_{z}-E I_{y}\right)\left(v^{(4)} \theta_{x}\right. \\
& +2 v^{\prime \prime \prime} \theta_{x}^{\prime}+v^{\prime \prime} \theta_{x}^{\prime \prime}+w^{(4)} \theta_{x}^{2}+4 w^{\prime \prime \prime} \theta_{x} \theta_{x}^{\prime}+2 w^{\prime \prime} \theta_{x} \theta_{x}^{\prime \prime} \\
& \left.+2 w^{\prime \prime} \theta_{x}^{\prime 2}\right)=0 \\
& E I_{z}\left(v^{(4)}+3 v^{\prime} v^{\prime \prime} v^{\prime \prime \prime}+v^{\prime \prime 3}+\frac{v^{(4)} v^{\prime 2}}{2}\right)-N\left(v^{\prime \prime}\right. \\
& \left.+z_{c} \theta_{x}^{\prime \prime}+y_{c}\left(\theta_{x} \theta_{x}^{\prime \prime}+\theta_{x}^{\prime 2}\right)\right)+\left(E I_{z}-E I_{y}\right)\left(w^{(4)} \theta_{x}\right. \\
& +2 w^{\prime \prime \prime} \theta_{x}^{\prime}+w^{\prime \prime} \theta_{x}^{\prime \prime}-v^{(4)} \theta_{x}^{2}-4 v^{\prime \prime \prime} \theta_{x} \theta_{x}^{\prime}-2 v^{\prime \prime} \theta_{x} \theta_{x}^{\prime \prime} \\
& \left.-2 v^{\prime \prime} \theta_{x}^{\prime 2}\right)=0 \\
& E I_{\omega} \theta_{x}^{(4)}-G J \theta_{x}^{\prime \prime}-\frac{3}{2} E I_{t} \theta_{x}^{\prime 2} \theta_{x}^{\prime \prime}-N\left(I_{0} \theta_{x}^{\prime \prime}\right. \\
& \left.-y_{c}\left(w^{\prime \prime}-v^{\prime \prime} \theta_{x}\right)+z_{c}\left(v^{\prime \prime}+w^{\prime \prime} \theta_{x}\right)\right)-\left(E I_{z}\right. \\
& \left.-E I_{y}\right)\left(v^{\prime \prime} w^{\prime \prime}-v^{\prime \prime 2} \theta_{x}+w^{\prime \prime 2} \theta_{x}\right)=0,
\end{aligned}
$$

where

$$
I_{t}=\int_{A}\left(\left(y-y_{c}\right)^{2}+\left(z-z_{c}\right)^{2}\right)^{2} \mathrm{~d} A-A I_{0}^{2} .
$$

Equations (11) through (13) can be precisely solved using the backward difference formulation [5]. For simply supported member under free warping, the displacement functions in bending and torsion are defined by sinusoidal function:

$$
\frac{v}{v_{0}}=\frac{w}{w_{0}}=\frac{\theta_{x}}{\theta_{0}}=\sin \frac{\pi x}{L}
$$

where $v_{0}, w_{0}$, and $\theta_{0}$ are the associated displacement amplitudes. Substituting (15) into (10) through (13) and employing Galerkin's approximation method yield

$$
\begin{gathered}
P_{z}\left(v_{0}+\frac{t^{2}}{8} v_{0}^{3}\right)-P\left(v_{0}+z_{c} \theta_{0}+\frac{4}{3 \pi} y_{c} \theta_{0}^{2}\right) \\
+\left(P_{z}-P_{y}\right)\left(\frac{8}{3 \pi} w_{0} \theta_{0}^{2}-\frac{3}{4} v_{0} \theta_{0}^{2}\right)=0,
\end{gathered}
$$

$$
\begin{gathered}
P_{y}\left(w_{0}+\frac{t^{2}}{8} w_{0}^{3}\right)-P\left(w_{0}-y_{c} \theta_{0}+\frac{4}{3 \pi} z_{c} \theta_{0}^{2}\right) \\
+\left(P_{z}-P_{y}\right)\left(\frac{8}{3 \pi} v_{0} \theta_{0}^{2}+\frac{3}{4} w_{0} \theta_{0}^{2}\right)=0, \\
P_{\theta} \theta_{0}+\frac{3 E I_{t}}{8 I_{0}} \theta_{0}^{3} t^{2} \\
-P\left(\theta_{0}-\frac{y_{c}}{I_{0}} w_{0}+\frac{z_{c}}{I_{0}} v_{0}+\frac{8 \theta_{0}}{3 \pi I_{0}}\left(w_{0} z_{c}+v_{0} y_{c}\right)\right) \\
-\frac{P_{z}-P_{y}}{I_{0}}\left(\frac{8 v_{0} w_{0}}{3 \pi}-\frac{3}{4} v_{0}^{2} \theta_{0}+\frac{3}{4} w_{0}^{2} \theta_{0}\right)=0,
\end{gathered}
$$

where $t=\pi / L, P_{y}=\pi^{2} E I_{y} / L^{2}, P_{z}=\pi^{2} E I_{z} / L^{2}$, and $P_{\theta}=$ $\left(E I_{\omega} \pi^{2}+G J\right) / I_{0} L^{2}$.

Equations (16) are high order nonlinear algebraic equations of four unknowns $P, v_{0}, w_{0}$, and $\theta_{0}$. Different from the Newton-Raphson method used by Mohri et al. [4], the homotopy continuation method is adopted to solve the equations in this paper. Through setting a series of $\theta_{0}$ in the software HOM4PS in literature [6], the corresponding loaddisplacement curves can be obtained, and the critical loads can be figured out.

Members with other boundary conditions have been analyzed similarly, and the derived mathematical formulation is as below.

For the member with two fixed ends, the approximate displacement function is defined by

$$
\frac{v}{v_{0}}=\frac{w}{w_{0}}=\frac{\theta_{x}}{\theta_{0}}=\cos \frac{2 \pi x}{L}-1 \text {. }
$$

For the member fixed at one end and free at the other end, the approximate displacement function is written as

$$
\frac{v}{v_{0}}=\frac{w}{w_{0}}=\frac{\theta_{x}}{\theta_{0}}=1-\cos \frac{\pi x}{2 L} .
$$

However, for the member fixed at one end and pinned at the other end, the approximate displacement function is defined as

$$
\frac{v}{v_{0}}=\frac{w}{w_{0}}=\frac{\theta_{x}}{\theta_{0}}=\frac{\sin (4.49 x / L)}{4.49}-\cos \frac{4.49 x}{L}+\frac{L-x}{L} .
$$

2.3. Nonlinearly Inelastic Buckling. The analytic solution of nonlinearly inelastic buckling load is difficult to be derived because elastic and plastic zones of sections are variable along longitudinal axis of compressive member. Location of shear center of each cross section is not constant in this case. Generally, the approximate solution is given by the theory of tangential modulus of elasticity. Finite Element Method is believed to be the most effective method for finding eigenvalue buckling load and nonlinearly inelastic buckling load $[2,3]$. 

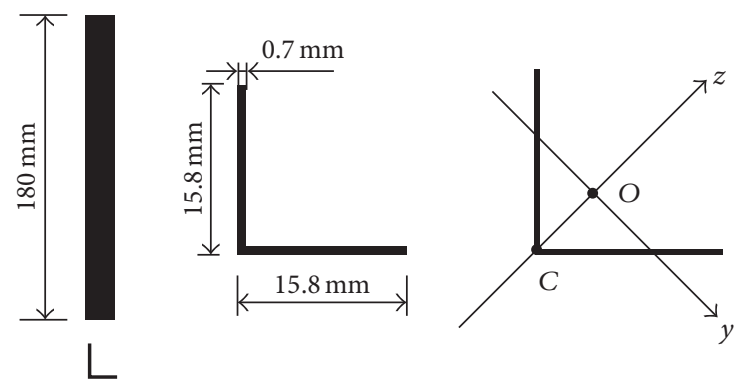

Figure 2: Profile of the angle.

\section{Experimental Analysis}

Experiment for investigating nonlinear-inelastic buckling loads and buckling modes of axially compressive thin-walled equilateral angles with pinned and fixed ends was carried out. The angles are made of cold rolled sheet of S235 steel with material properties of $E=206 \mathrm{GPa}, v=0.3$, and $\sigma_{y}=360 \mathrm{MPa}$, respectively. The compressive member is $180 \mathrm{~mm}$ long with angle section as shown in Figure 2. For the occurrence of inelastic buckling, the slenderness of the member is $\lambda=180 \mu / 3.1717$, where $\mu$ is the effective length factor. Under the coordinate axes $y$ and $z$ and shear point $C$ $(0,-5.478 \mathrm{~mm})$ shown in Figure 2, geometric parameters are determined; namely, $I_{y}=218.3 \mathrm{~mm}^{4}, I_{z}=869.3 \mathrm{~mm}^{4}, A=$ $21.7 \mathrm{~mm}^{2}, I_{0}=80.12 \mathrm{~mm}^{2}, I_{\omega}=0 \mathrm{~mm}^{6}, J=3.57 \mathrm{~mm}^{4}$, and $I_{t}=111345 \mathrm{~mm}^{6}$, respectively. Strain gauges were mounted on the surface of each edge at the position of $L / 4, L / 2$, and $3 L / 4$ to the bottom, where $L$ is the length of the member. The axial load is measured by sensor of TGZ-100 at support, and deflections in the middle span are recorded by dial indicator.

In the experiment, the angle only bent in one direction without torsion when it is pinned at two ends. The primary failure mode is flexural-torsional inelastic buckling as shown in Figure 3. The local buckling caused by torsion occurred first in the lower part of the member, and then overall buckling happened. From the slenderness ratio of 56.75, it also can be predicted that inelastic buckling would happen for the specimen. The critical buckling loads and the loaddisplacement curves of the specimen are obtained as shown in Figure 4.

\section{Finite Element Analysis}

Buckling load and buckling mode can be identified by finite element software through either eigenvalue buckling analysis or nonlinear buckling analysis. The eigenvalue buckling analysis is applicable to determine the buckling strength of an ideally linear-elastic structure where nonlinear terms of material and geometry are linearized to keep the stiffness matrix unchanged during load progressing. Buckling of thinwalled compressive members is usually analyzed by using beam and shell elements. Mohri [7, 8] has developed the 3Dbeam element with two nodes and seven degrees of freedom per node to analyze the linear and nonlinear-elastic buckling behavior of thin-walled beams with arbitrary cross sections and verified the accuracy by the model of shell element. Study

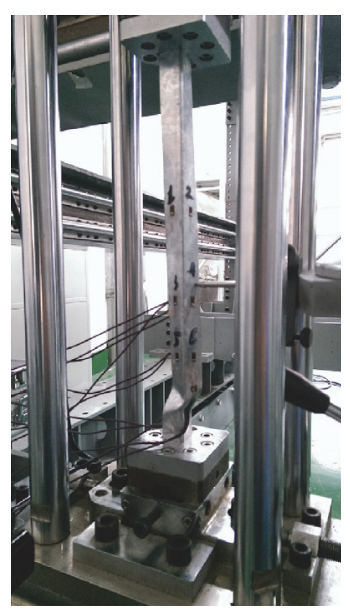

FIGURE 3: Axial compressive test of an angle.

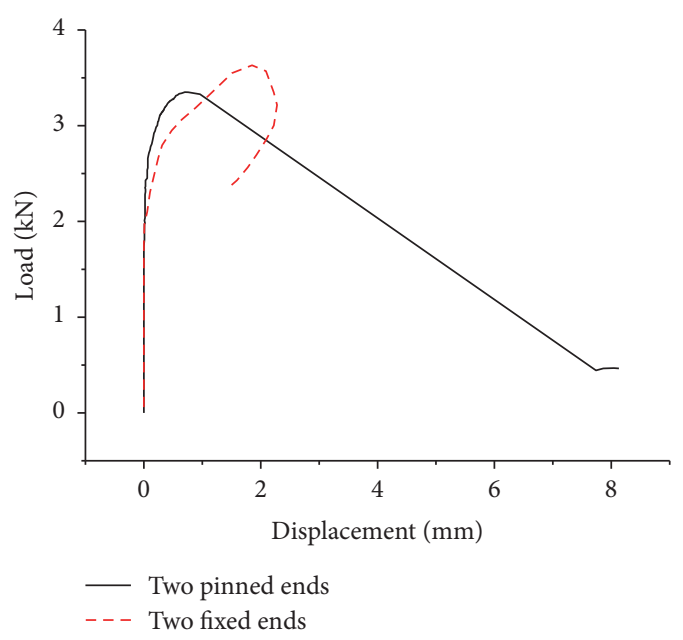

FIGURE 4: Load-displacement curves of the specimen.

by Zhang and Tong $[9,10]$ showed that the Wagner effect of bending could not precisely calculated by beam elements used in ANSYS and ABAQUS, and a proposed thin shell element model is superior to the beam element for flexuraltorsional buckling analysis of thin-walled beams and beamcolumns of monosymmetric section and tapered section.

4.1. Nonlinearly Elastic Buckling Analysis. The specimen used in the experiment is of $180 \mathrm{~mm}$ length with small slenderness; therefore, the inelastic buckling occurs. In this section, for investigating the numerical solution of elastic buckling, the length of the computational model of the angle is deliberately assigned to be $1000 \mathrm{~mm}$. Elements of Beam189 and Shell93 in ANSYS are used to solve elastic buckling load as below.

4.1.1. Beam Model. According to the analytical solution: the foregoing linear-elastic equation (2) and nonlinear-elastic equations (16), the $P-\theta_{0}$ curves of the angles with four different constraints are obtained as shown in Figures 5-8. It can be seen that the postbuckling behavior can be revealed by the nonlinear analytical solution, and the buckling loads 


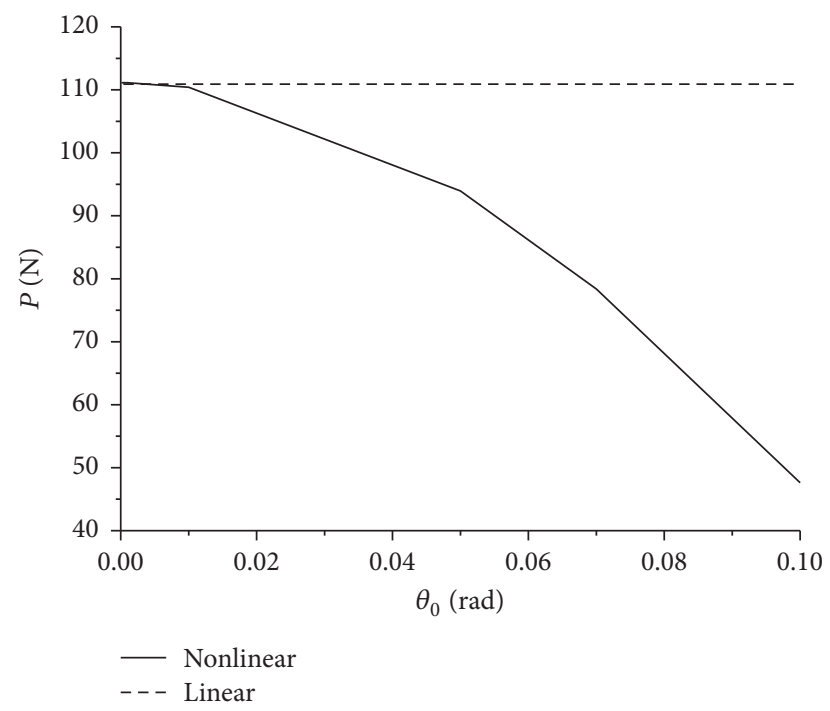

Figure 5: $P-\theta_{0}$ curve of member with fixed and free ends.

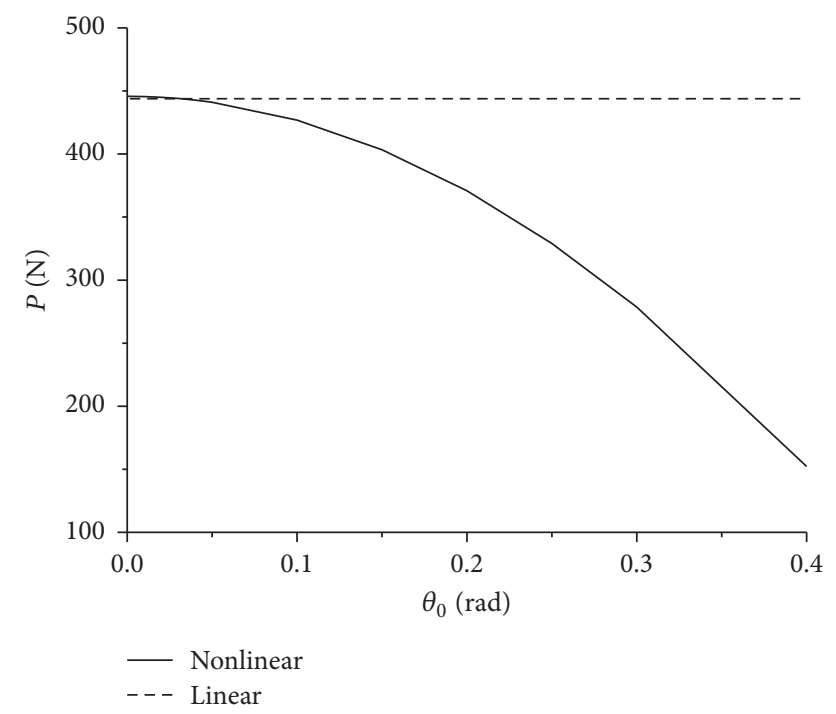

Figure 6: $P-\theta_{0}$ curve of member with two pinned ends.

in the extreme point instability are different from the firstorder eigenvalue in linear solution and numerical solution with beam element.

In the buckling analysis with Beam189 in ANSYS, it is default that the centroid of the section is the coordinate origin. Axially compressive load is applied along the longitudinal centroidal axis. Constraint is applied at the centroid of each end.

The numerical buckling loads of the angles with different end-constraints are compared with the analytic values and listed in Table 1. It can be seen that the first-order eigenvalues from numerical analysis with beam element are close to the linear analytical results, and the buckling loads considering geometrically nonlinear instability are larger than those obtained from the classical eigenvalue buckling analysis since the translation/rotation coupling, higher order terms of displacements in governing equations, and the shorter effect

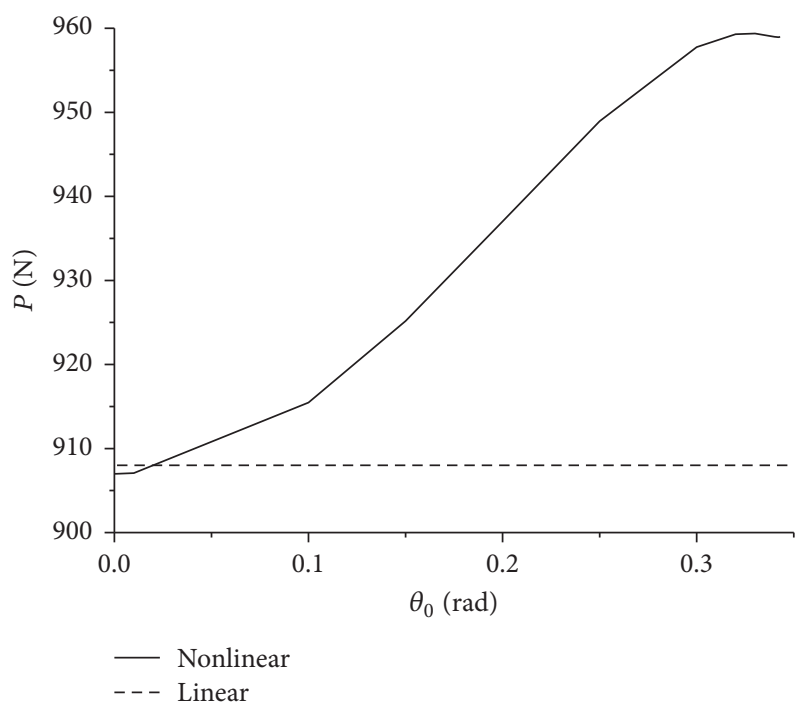

Figure 7: $P-\theta_{0}$ curve of member with fixed and pinned ends.

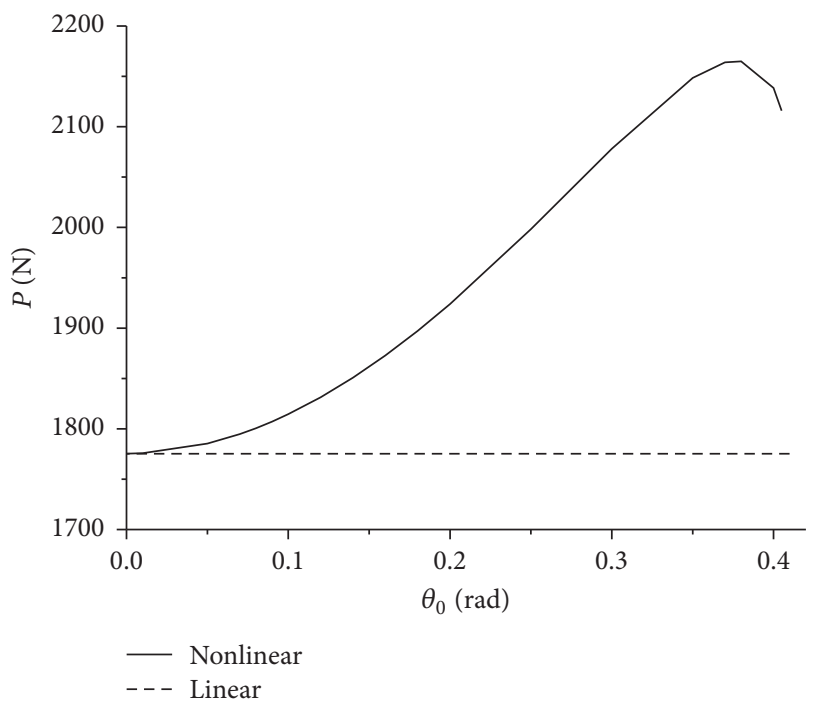

FIgURE 8: $P-\theta_{0}$ curve of member with two fixed ends.

are all counted. It also can be found that the elastic buckling loads of the member with $1000 \mathrm{~mm}$ length listed in Table 1 are much smaller than the inelastic buckling loads obtained in the experiment, where the length of the member is $180 \mathrm{~mm}$.

4.1.2. Shell Model. When the compressive angle is discretized with Shell93 element, the axial load cannot be placed directly at the centroid for it is out of the material of the cross section. In this case, an evenly distributed load equivalent to axial load is applied on the end section to avoid stress concentration.

For the member with angle section, the boundary condition is achieved by fixing transverse displacements of the centroid [11, 12], the corner points, or the entire cluster of nodes on the end sections [13]. When the transverse displacement of the centroid is constrained, an auxiliary plate has to be added at the end cross section for transfer of the load. A hard point with fixed transverse displacements should 
TABLE 1: Comparison of buckling loads obtained from analytical and numerical solution $(\mathrm{kN})$.

\begin{tabular}{lcccr}
\hline \multirow{2}{*}{ Constraints } & \multicolumn{2}{c}{ Analytical results } & Numerical results with beam elements (NB) & Error \\
& Linear (TL) & Nonlinear (TN) & (NB/TL) & $(\mathrm{NB} / \mathrm{TN})$ \\
\hline Fixed and free ends & 0.1109 & 0.1111 & 0.1109 & $-0.18 \%$ \\
Two pinned ends & 0.4438 & 0.4457 & 0.4436 & $-0.05 \%$ \\
Fixed and pinned ends & 0.9080 & 0.9594 & 0.9068 & $-0.47 \%$ \\
Two fixed ends & 1.7753 & 2.1649 & 1.7714 & $-0.13 \%$ \\
\hline
\end{tabular}

TABLE 2: Buckling loads from shell model with different boundary treatments.

\begin{tabular}{|c|c|c|c|c|c|c|c|}
\hline Constraints & Beam elements & Centroid constrained & Error & Corner constrained & Error & All nodes constrained & Error \\
\hline Fixed and free ends & 0.1109 & 0.1183 & $6.67 \%$ & 0.1183 & $6.67 \%$ & 0.1183 & $6.67 \%$ \\
\hline Two pinned ends & 0.4436 & 0.473 & $6.63 \%$ & 0.472 & $6.40 \%$ & 0.965 & $117.54 \%$ \\
\hline Fixed and pinned ends & 0.9068 & 0.966 & $6.53 \%$ & 0.966 & $6.53 \%$ & 0.965 & $6.42 \%$ \\
\hline Two fixed ends & 1.7714 & 1.771 & $-0.02 \%$ & 1.092 & $-38.85 \%$ & 1.092 & $-38.85 \%$ \\
\hline
\end{tabular}

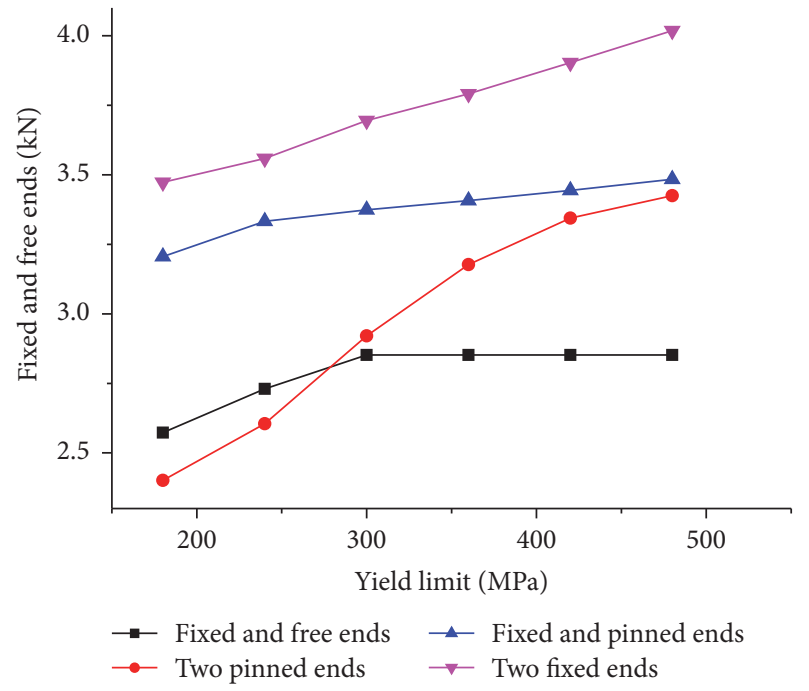

FIGURE 9: Effect of yield stress on buckling load.

be created at the position of the centroid on the plate. If the member is fixed at ends, the rotational angles of the hard point should be further restricted.

The nonlinearly elastic buckling loads obtained with these three treatments of boundary conditions are presented and compared with those from the beam model, as shown in Table 2. It is found that the critical loads determined from the model of centroid constrained are bigger than those from the beam model since the rigidity of the member is improved by adding plates at the ends. If all nodes on the two ends of the angle are pinned constraints, the stronger boundary treatment results in higher buckling load. The critical loads obtained from fixed centroid and fixed corner points are close, though the former treatment of boundary is more ideal than the latter. Therefore, it is suggested that restriction of the centroid with auxiliary end plates should be used in nonlinearly elastic buckling analysis.

4.2. Inelastic Buckling Analysis. The angles tested in the experiment are modeled in the inelastic buckling analysis since the actual inelastic buckling occurred. Shell element is usually applied when geometrically and physically nonlinearinelastic buckling is analyzed. Effects of scale factor of initial defect, yield strength, loading mode, treatment of constraint, and rib on numerically buckling analysis are studied as well. In the environment of ANSYS solution control, the option of large deformation is specified. Initial defects are imposed through the command UPGEOM. The first-order buckling mode of displacement obtained from eigenvalue buckling analysis is multiplied by a scale factor and is imposed on the nonlinear model afterwards. The arc-length method is applied in the solution [14].

4.2.1. Effects of Yield Stress Limit and Scale Factor. Inelastic buckling load is affected by yield strength of material. The buckling load improves with the increase of yield strength, as shown in Figure 9. For comparison of the numerical and experimental results, the constitutive model of material is selected to be bilinear isotropic hardening with yield strength of $360 \mathrm{MPa}$ in the following computation.

The influence of the scale factor on the buckling load is analyzed and illustrated in Figure 10. It is noted that the buckling load decreases with the increase of scale factor but is not remarkable. Based on the current codes for design of steel structures, an equivalent length of the member as the initial geometrical defect is considered when the overall stability of compressive steel member is designed [15]. In the corresponding Chinese Code, it is suggested that the initial geometrical defect is given in the shape of the first-order modal of elastic buckling, where we let the initial deflection, namely, the production of the scale factor with the maximum deflection under the first-order modal, be equal to $L / 1000$ [16]. The maximum deflections are different for the members with different end-constraints, but the buckling loads are little affected by the small value of scale factor, which is about 0.008 in the discussed problem.

4.2.2. Effects of Other Factors. As previously mentioned, the boundary condition of the compressive angle can be treated by constraining the centroid, corner nodes or the entire 


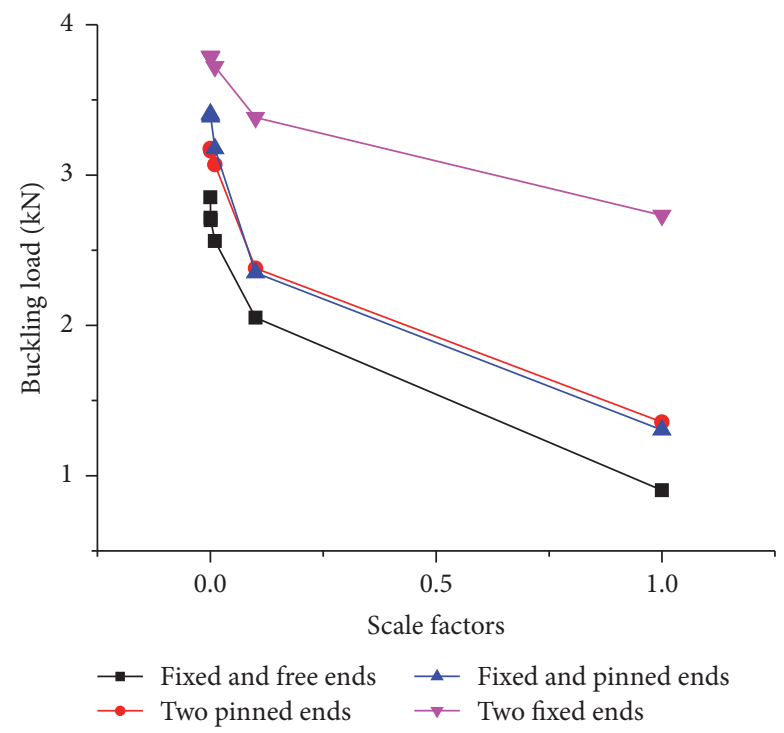

FIgURE 10: Effect of scale factor on buckling load.

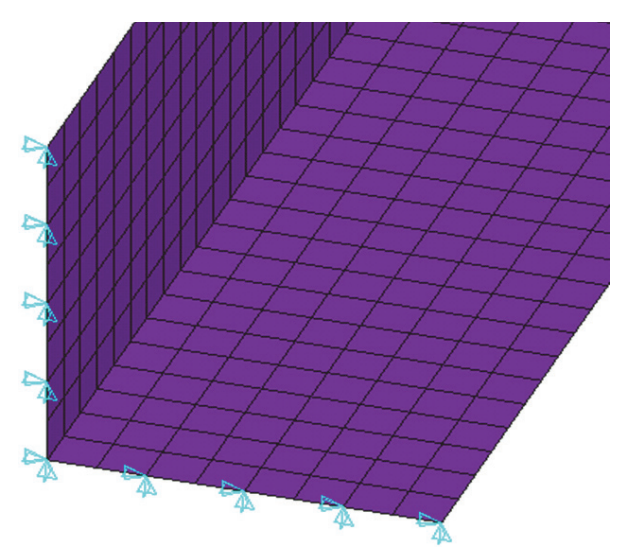

FIGURE 11: The pinned constraint in computation.

nodes on the end section when shell element is applied. In the inelastic buckling analysis, it is found that the buckling load of $3.479 \mathrm{kN}$ is greater than the theoretical $3.172 \mathrm{kN}$, and serious stress concentration occurs as the centroid of the added plate is constrained. When the corner nodes are constrained, the buckling load of $1.482 \mathrm{kN}$ is much smaller than the theoretical value, which indicates that the treatment of boundary condition is too weak to represent the real pinned support. Through trial calculations, the buckling load is the closest to the theoretical value and the one with the beam model when nine uniform nodes are constrained as shown in Figure 11.

A convenient measure preventing local buckling is to add a transverse rib in the longitudinal direction of the angle. Zhang proposed modeling the rib separately from the angle, and the transverse degrees of freedom at joint were coupled to avoid increasing stiffness of the structure [10]. To investigate the overall instability, one rib is added in the same way at the middle of the member as shown in Figure 12 based on the slenderness ratio of the angle. The computational results

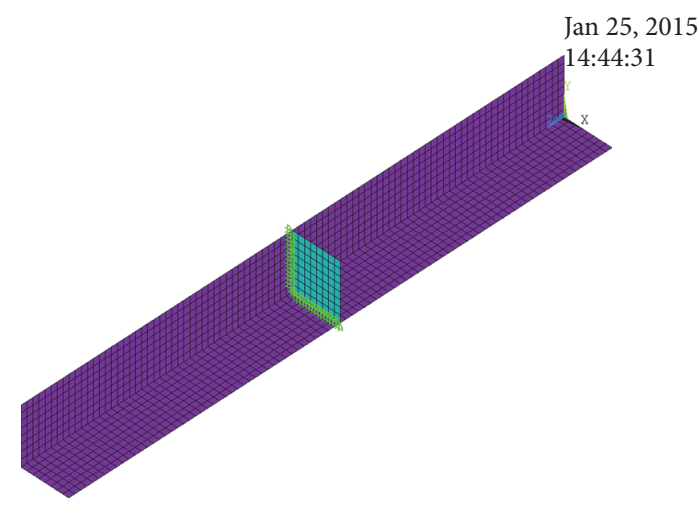

FIgURE 12: Angle with a rib in the middle.

reveal that there is neither obvious change in buckling load nor occurrence of locally large deformation.

The computational buckling load is also affected by the ways of loadings. The nodal forces on the end section are not uniform when certain displacement is assigned to a specific node; the descending segment of load-displacement curve can be generated. By contrast, there is no obvious descending segment of load-displacement curve when a uniformly distributed force is applied on each node. The inflection point on the curve of load-displacement can be found whose ordinate gives the ultimate load of overall buckling.

4.2.3. Discussion of Numerical Results. Based on the foregoing investigation, the inelastic critical loads of the tested angle are obtained via nonlinear buckling analysis of shell element in ANSYS, as shown in Table 3. The theoretical nonlinear-elastic results, the loads of eigenvalue buckling determined using beam and shell models are presented as well for comparison. The following can be found.

(1) The tested buckling loads are bigger than the eigenvalue buckling loads determined by shell model, close to beam model, due to the pinned support with torsional and flexural restriction in the experiment. The theoretical elastic buckling loads are smaller than the first-order eigenvalue buckling loads since the nonlinear coupling terms are ignored in the theoretical analysis, even though the two methods are similar.

(2) Shell element is appropriate for analyzing overall stability of thin-walled member from the point of geometric similarity. The eigenvalue buckling loads through shell model are smaller than those of beam model since the Wanger's effect in moment of thinwalled member cannot be admitted into beam model, leading the numerical results bigger than the real, which is not suitable for buckling analysis for a member with monosymmetric section.

(3) The buckling load determined through nonlinear buckling analysis is different from eigenvalue analysis via shell model. Load-displacement curves of 
TABLE 3: Nonlinear buckling load obtained by different methodologies (kN).

\begin{tabular}{lccccc}
\hline Constraints & Test & Analytic results & Beam element (eigenvalue) & Shell elements (eigenvalue) & Shell elements (nonlinear) \\
\hline Fixed and free ends & & 2.157 & 3.1844 & 2.998 & 2.852 \\
Two pinned ends & 3.13 & 3.172 & 3.447 & 3.283 & 3.093 \\
Fixed and pinned ends & & 3.359 & 3.581 & 3.323 & 3.231 \\
Two fixed ends & 3.40 & 3.444 & 3.63 & 3.528 & 3.733 \\
\hline
\end{tabular}

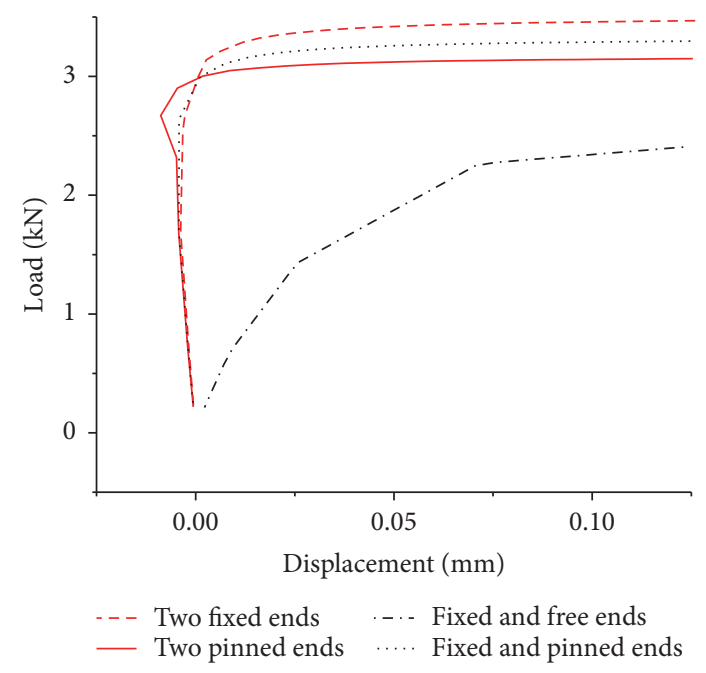

Figure 13: Load-displacement curve of nonlinearized inelastic buckling.

the angles with various constraints in nonlinearinelastic buckling analysis are obtained as shown in Figure 13. This shows that the stability of the angles improves with the strengthening of constraints. The nonlinearized inelastic buckling loads may be bigger or smaller than those of eigenvalue buckling loads for the members with different constraints and scale factors; see the last column in Table 3, which gives the similar tendency as [17].

\section{Conclusion}

The computational methods of buckling loads of thin-walled members with open sections have been carried out in this paper. From the analysis of nonlinearly elastic and inelastic buckling load computation, the following is found.

Nonlinearly elastic buckling loads determined from mathematical formula and beam model are close and possess high precision. Mathematical solution of higher order differential equations is complicated. So for the member with simple deflection, the method in this paper is acceptable; otherwise, difference method is generally applied. When shell model is used in the computation, the restriction of the centroid with auxiliary end plates is more ideal than other treatments of boundary conditions.

Numerical solution is the most effective method for the nonlinearly inelastic overall buckling analysis. The effects of loading mode, treatment of boundary condition, adding rib, initial defect, and yield strength on computational results should be noted when shell element is applied. It has been found that the eigenvalue buckling analysis through shell model possesses high precision from the study of this paper. The nonlinear buckling load calculated by shell element may be bigger or smaller than eigenvalue buckling load, which is influenced by the yield strength of the material and scale factor of initial defect.

\section{Nomenclature}

$\begin{array}{ll}A: & \text { Cross section area } \\ E: & \text { Young's modulus } \\ G: & \text { Shear modulus } \\ I_{0}: & \text { Polar moment of inertia about shear center } \\ I_{R}: & \text { Fourth moment of inertia about shear } \\ & \text { center } \\ I_{t}: & \text { Higher order shortening constant } \\ I_{y}, I_{z}: & \text { Principle moment of inertia about } y \text { and } z \\ I_{\omega}: & \text { axes } \\ J: & \text { Warping constant } \\ L: & \text { St-Vant torsion constant } \\ P: & \text { Member length } \\ U: & \text { Compression axial load } \\ W: & \text { Stress energy } \\ u, v, w: & \text { Work of conservative loads } \\ & \text { Shear displacement component of shear } \\ u_{M}, v_{M}, w_{M}: & \text { Displacement components of } M \text { in } x, y \\ v_{0}, w_{0}: & \text { and } z \text { axes } \\ x, y, z: & \text { Displacement amplitudes of } v \text { and } w \text { in } \\ y_{c}, z_{c}: & \text { numerical analysis } \\ \varepsilon_{x x}, \varepsilon_{x y}, \varepsilon_{x z}: & \text { Principal coordinate of } M \text { in global } \\ \mu: & \text { reference } \\ \omega: & \text { Effective length factor } \\ \theta_{0}: & \text { Warping coordinate } \\ \theta_{x}: & \text { Torsion angle } \\ & \text { Torsion amplitude in numerical analysis. } \\ & \end{array}$

\section{Competing Interests}

The authors declare that there is no conflict of interests regarding the publication of this paper. 


\section{Acknowledgments}

The authors would like to acknowledge the financial support of the Natural Science Fund of Liaoning Province, China (2014020008).

\section{References}

[1] S. H. Bao and J. Zhou, Structural Mechanics of Thin-Walled Bar, China Architecture \& Building Press, Beijing, China, 1991.

[2] J. Chen and H. Chen, Stability of Steel Structures: Theory and Design, China Electric Power Press, Beijing, China, 2009.

[3] G. M. Liu, R. X. Zhang, and T. S. Zhang, Application of Structural Stability Calculation, Science Press, Beijing, China, 2004.

[4] F. Mohri, L. Azrar, and M. Potier-Ferry, "Flexural-torsional post-buckling analysis of thin-walled elements with open sections," Thin-Walled Structures, vol. 39, no. 11, pp. 907-938, 2001.

[5] E. J. Sapountzakis and V. J. Tsipiras, "Warping shear stresses in nonlinear nonuniform torsional vibrations of bars by BEM," Engineering Structures, vol. 32, no. 3, pp. 741-752, 2010.

[6] T. L. Lee, T. Y. Li, and C. H. Tsai, "HOM4PS-2.0, a software package for solving polynomial systems by the polyhedral homotopy continuation method," Computing, vol. 83, no. 2-3, pp. 109-133, 2008.

[7] F. Mohri, A. Eddinari, N. Damil, and M. Potier Ferry, "A beam finite element for non-linear analyses of thin-walled elements," Thin-Walled Structures, vol. 46, no. 7-9, pp. 981-990, 2008.

[8] F. Mohri, A. Brouki, and J. C. Roth, “Theoretical and numerical stability analyses of unrestrained, mono-symmetric thin-walled beams," Journal of Constructional Steel Research, vol. 59, no. 1, pp. 63-90, 2003.

[9] L. Zhang and G. S. Tong, "Finite element modelling of thinwalled members in overall stability analysis," Journal of Zhejiang University (Engineering Science), vol. 45, no. 3, pp. 531-538, 2011.

[10] L. Zhang, A Theory of Stability for Thin-Walled Members Considering the Effects of Transverse Stresses and Its Applications, Zhejiang University, Hangzhou, China, 2005.

[11] J. Chen, Buckling Behavior of Single Cold-Formed Angle under Axial Load, Xian University of Architecture and Technology, Xi'an, China, 2004.

[12] H.-Y. Ban, G. Shi, and Y.-J. Shi, "Investigation on design method of overall buckling behaviour for Q420 high strength steel equal-leg angle members under axial compression," Engineering Mechanics, vol. 31, no. 3, pp. 63-71, 2014.

[13] X. X. Hong, The Stability of the Cold-Formed $60^{\circ}$ Equilateral Single Angle under Compression, Chang'an University, Xian, China, 2008.

[14] J. F. Zhu and H. P. Yang, "Accelerated arc-length method for solving postbuckling path of structures," Journal of Dalian University of Technology, vol. 34, no. 1, pp. 17-22, 1994.

[15] G. Shi, Y. Q. Shi, and Y. Q. Wang, "Analysis on overall buckling behavior of ultra-high strength steel columns by ANSYS," Journal of Jilin University (Engineering and Technology Edition), vol. 39, no. 1, pp. 113-118, 2009.

[16] National Standard Specification, Code for Design of Steel Structures (GB 50017-2003 PRC), China Plan Press, Beijing, China, 2003 (Chinese).

[17] Q. H. Han, H. Jin, J. Ai, and X. Y. Liu, "Analysis of the overall buckling load for engineering structure," Journal of Tianjin University, vol. 38, no. 12, pp. 1051-1057, 2005. 


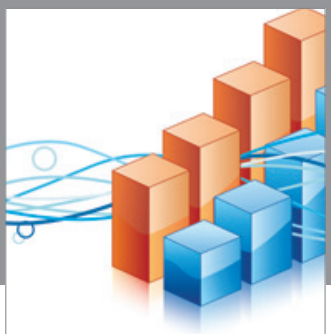

Advances in

Operations Research

vatem alat4

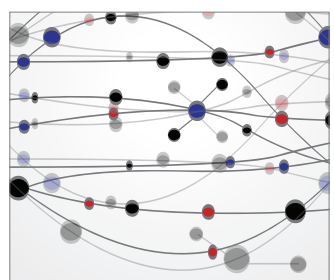

\section{The Scientific} World Journal
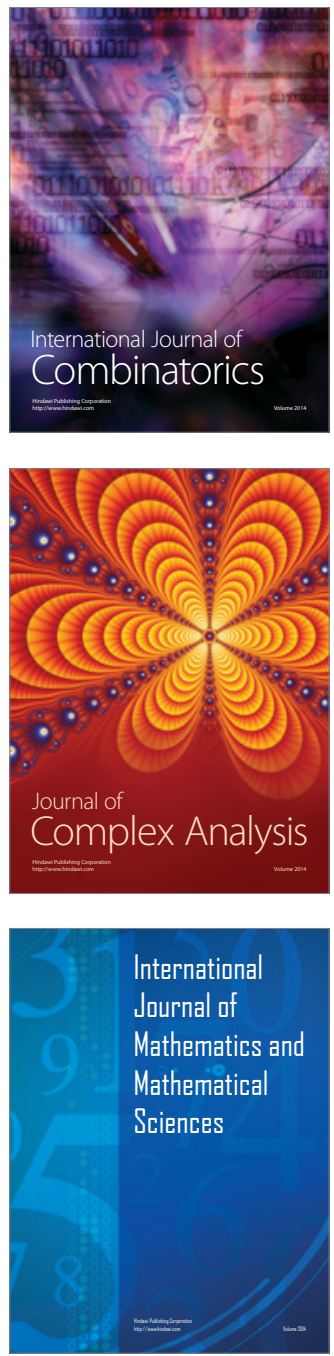
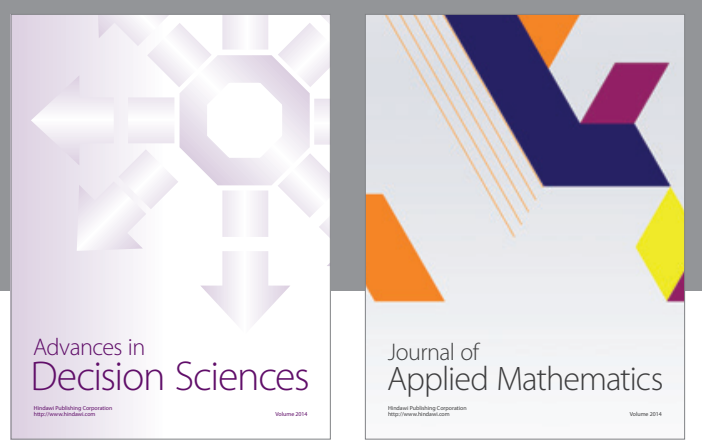

Algebra

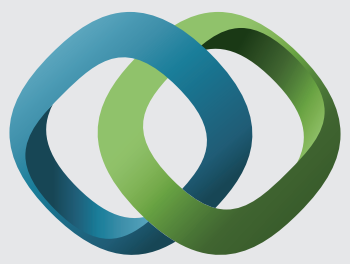

\section{Hindawi}

Submit your manuscripts at

http://www.hindawi.com
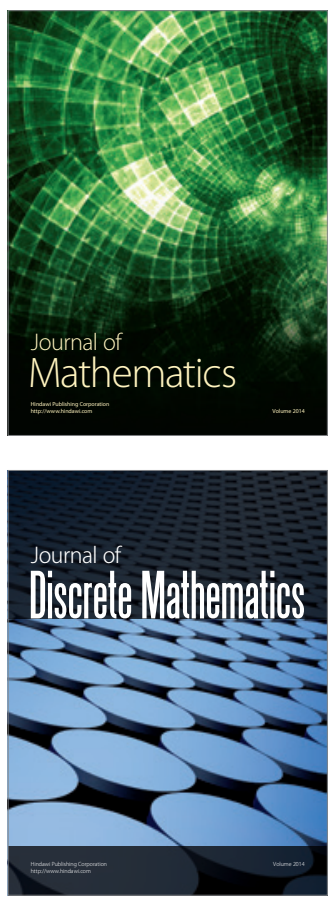

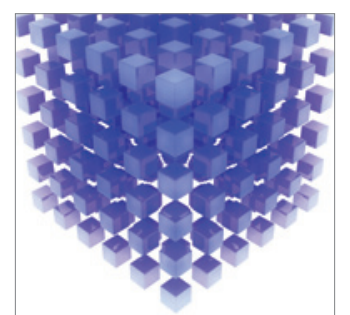

Mathematical Problems in Engineering
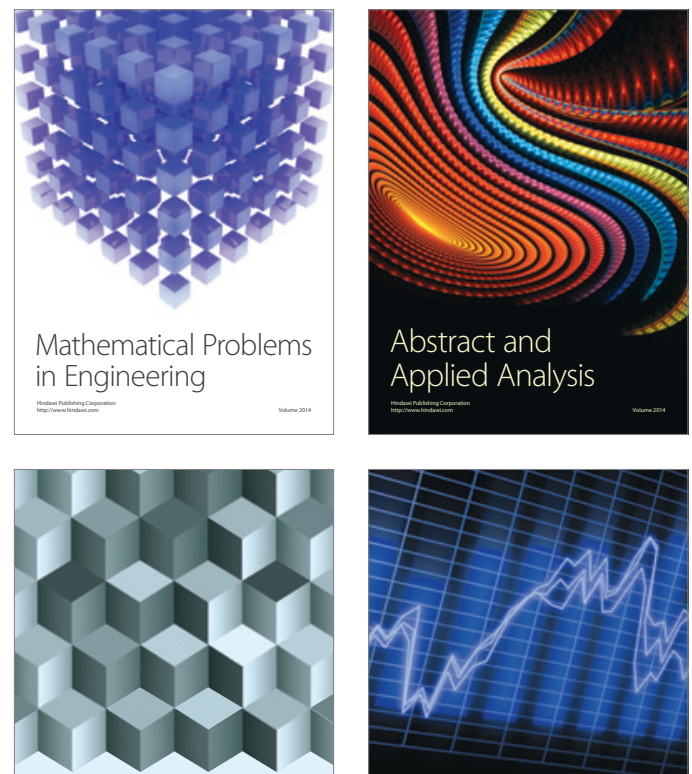

Journal of

Function Spaces

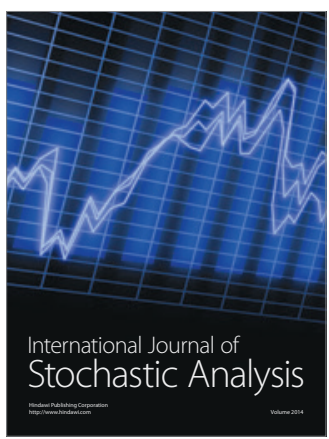

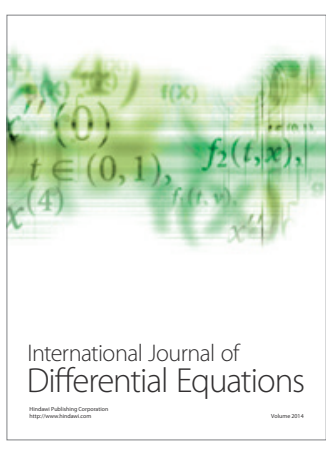
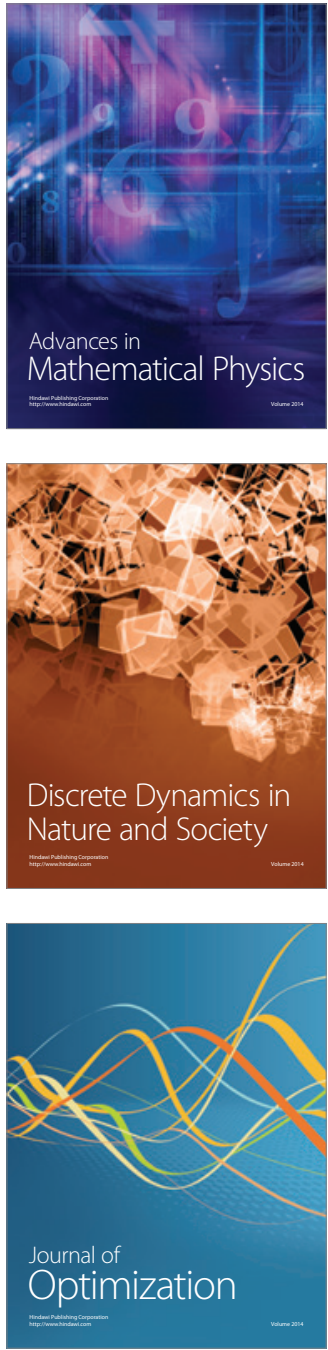